\title{
Enterprise architecture management's impact on information technology success
}

\author{
Robert Lagerström, Teodor Sommestad, Markus Buschle, Mathias Ekstedt \\ Industrial Information and Control Systems \\ The Royal Institute of Technology \\ Osquldas väg 12, 10044, Stockholm Sweden \\ \{robertl,teodors,markusb,mek101\}@ics.kth.se
}

\begin{abstract}
Both practitioners and researchers put forward enterprise architecture management as a mean for achieving success with information technology. Many arguments have been put forward to support the benefits claimed to arise from mature enterprise architecture management and a considerable amount of literature describes the components of mature (successful) enterprise architecture management. However, few studies have empirically tested whether the enterprise architecture management activities impact organizations' success with information technology. This paper tests the relationship between organizations' success with information technology and enterprise architecture management activities. Significant correlations are found between these variables.
\end{abstract}

\section{Introduction}

Enterprise Architecture (EA) has during the last two decades been put forward as an effective approach for business and information systems management [1]. Support for tasks such as product planning, business development, and business process- and information systems consolidation are for instance suggested to be offered by enterprise architecture [2]. At the core of enterprise architecture lies the idea that information systems and the business should be considered holistically and consistently, typically by the use of conceptual (architecture) models [3].

However, how and exactly for what purposes enterprise architecture is used varies greatly. Some organizations use it for information technology (IT) concerns alone, others for both business and IT. Some focus on achieving a holistic and unified governance approach and others care more for the modeling issues and try to achieve consistent and all encompassing models. Some use enterprise architecture primarily for documenting the current state of affairs, whereas others see it as planning and decision making support. Yet others see enterprise architecture mainly as a means for communication. Many, of course, also use EA for more than one of these different purposes. The general belief among both practitioners and researchers is that EA surely can enhance the present and future performance of the business, by satisfying several needs for several stakeholders in the organization.

A line of criticism that has been directed mainly from practitioners towards EA during the last couple of years is that it is a very heavy approach. There are lots of steps that need to be taken, if the state of the art methods are followed and there is an extensive amount of models to be developed according to many frameworks. In many cases there seem to be an impression that enterprise architecture is failing to deliver the promised benefits since they cannot be delivered quickly and cheaply enough to the organization. This criticism could for instance be traced in the EA communities trying to become more lightweight [4][5]. Even larger more all encompassing frameworks such as the TOGAF [6] are also making very clear explicit statements that the framework needs to be tailored before it is applied. Lately, a web 2.0 inspired approach is starting to grow [7]. Gartner on their side predicts that EA has just past the bottom of the "Through of Disillusionment" phase on their famous Hype Cycle [8].

However, on a deeper and more fundamental level an eligible question is if the fundamental assumptions about enterprise architecture as an effective management support tool are correct. Many (by all means sound) arguments have been made often implicitly to support this assumption, but few empirical studies on this issue can be found.

This article reports on results from a large survey conducted among Swedish practitioners involved in enterprise architecture management (EAM). The survey investigated the current scope and maturity as 
well as experienced benefits of enterprise architecture management.

The remainder of this paper is structured as follows. Section two discusses related works in the field of enterprise architecture and in the impact of enterprise architecture management. Section three presents the research methodology and the hypotheses tested. Section four presents the result. In Section five this result is discussed and in section six conclusions are drawn.

\section{Related works}

The practice and theory of enterprise architecture management is well described in literature. This includes textbooks (e.g. [9] and [10]), conference and workshop proceedings (e.g. HICSS. EDOC and TEAR), journal articles (e.g. [11] and [12], frameworks (e.g. TOGAF [6] and Modaf [13]) and technical reports (e.g. [14]). Literature often provides a rationale for initiating enterprise architecture efforts and explains how to make them successful.

There are several descriptions of the benefits gained from EA practices. The first chapter in [9] states 13 business benefits of enterprise architecture planning and 12 benefits of planned IT systems. A good enterprise architecture will according to [6] and [15] provide a more efficient IT operation, lead to better return on existing investments, reduce risks associated with future investments and make procurement faster, simpler and cheaper. According to TOGAF [6] an effective enterprise architecture is an indispensible mean to achieve competitive advantage through information technology. In fact, TOGAF states that it is critical to business survival and success. Further, according to Zachman [16] systems designed according to an EA are relatively economical, quickly implemented, and easier to design and manage.

Evidence supporting the benefits from good enterprise architecture management are however sparse. In fact, none of the abovementioned texts presents evidence that support the claimed benefits.

Ross et al. [1] describes a model where enterprise architecture maturity classified into four stages: business silos, standardized technology, optimized core and business modularity. Advancing in these stages will lead to reduced IT costs, increased IT responsiveness, improved risk management, increased management satisfaction and increased strategic business impact [1]. These relationships are also supported by data. However, no peer-reviewed publication can be found where these results are presented.
The result presented in Ross et al. [1] indicated that there is a relationship between a mature enterprise architecture and business benefits. Enterprise architecture management is seen as the path to a mature enterprise architecture. For this purpose, several frameworks have been developed to evaluate the maturity of enterprise architecture management. Including [14], [17], [18], [19], [20], and [21].

In contrast to the maturity stages defined in [1] these maturity models describe how to measure and improve the maturity of enterprise architecture management activities, and not the architectures themselves.

Naturally, there is a significant overlap between the elements discussed in different maturity models. For example, all ([14], [17], [18], [19], [20], and [21]) state that the existence of an architecture function within the organization is important and that key architecture roles should be defined. To monitor conformance to the architecture standards, constantly evaluated enterprise architecture management processes and management of the quality of these processes are also discussed in all these maturity models. Furthermore, they all stress the need to involve, and communicate with, key stakeholders within the organization. The use of an agreed reference method for enterprise architecture management leads to maturity in [18], [19], and [20]. In [18], [19], and [14] well defined enterprise architecture management processes are associated with maturity and in [14] a more process based enterprise architecture management is associated with higher maturity than management seen as a project.

These enterprise architecture management maturity models describe the process of how good enterprise architectures should be developed. Good enterprise architecture is in turn also attributed to several benefits. This includes faster procurements, increased return on investments and more efficient IT operations. This theory is found in both academic and practitioner-oriented literature. Yet, there are few empirical studies that confirm the theory that mature enterprise architecture management leads to these benefits.

Slot et al. [22] have tested if well-defined solution architectures impact project success variables. They find that a solution architecture positively influence: schedule delays, budget overrun, variance in project time frame and budget overrun, if the project delivers as expected and the technical fit. The definition of a target architecture, or a to-be architecture, is a fundamental part of enterprise architecture management (see for example [6]). The study described in [22] is however made in the context of 
software development projects and no similar study has been found that generalizes these findings to an enterprise perspective.

Boh and Yellin [11] present a comprehensive study treating the relationship between enterprise architecture governance and the resulting enterprise architecture. Based on a survey responded by 90 organizations they test if governance mechanisms for enterprise architecture impacts the use and conformance to enterprise architecture standards. They also test if conformance to enterprise architecture standards impact four outcomes in the enterprise architecture: the heterogeneity in the IT infrastructure, the replication of services in the IT infrastructure, business application integration and enterprise data integration. Their result confirms the hypothesis that governance mechanisms have a beneficial impact on the use of enterprise architecture standards and the four outcomes.

As Boh and Yellin [11], this paper presents a test of enterprise architecture management's impact on organizations. Unlike Boh and Yellin, however, this paper tests outcomes in terms of direct business benefits. Namely the percent of IT projects that are successful, the duration of IT procurement projects, and how satisfied the business is with the organizations information technology.

Further, unlike Boh and Yellin this paper tests the outcomes against the maturity of the enterprise architecture management function and the duration for which this function has existed. As described above the maturity models developed for enterprise architecture management activities describe a large number of variables that indicate maturity. In this paper enterprise architecture maturity is measured through variables that are present in several maturity frameworks. The measurement instrument (survey) used in this study is an adapted version of the one used in [23][24][25]. However, none of the previous studies with this survey instrument test the impact of enterprise architecture management of IT success in enterprises.

\section{Research methodology}

The overall aim of the presented study is to test the general hypothesis that Enterprise Architecture Management activities has a positive impact on ITsuccess.

To assess this impact three main hypothesis evaluated through nine sub hypotheses are tested. These are, as outlined in Table 1, derived from three variables of IT-success and three variables of enterprise architecture management activities.
The rationale for these hypotheses and their operationalization is described below.

\subsection{IT-success}

No academic research papers on enterprise architecture have been found that explicitly describe tests for the success of enterprise architecture activities. Nor are such tests proposed in the books and standards available.

Table 1. Hypotheses tested.

\begin{tabular}{|c|c|c|c|c|}
\hline & \multicolumn{3}{|c|}{ IT-success } \\
\hline & & 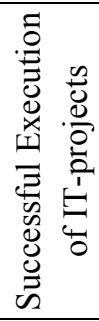 & 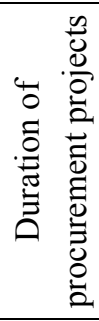 & 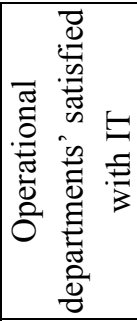 \\
\hline \multirow{3}{*}{ 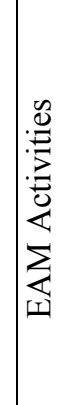 } & $\begin{array}{c}\text { Existence of } \\
\text { EAM }\end{array}$ & H1.1 & $\mathrm{H} 1.2$ & H1.3 \\
\hline & $\begin{array}{c}\text { Amount of } \\
\text { time worked } \\
\text { with EAM }\end{array}$ & $\mathrm{H} 2.1$ & $\mathrm{H} 2.2$ & $\mathrm{H} 2.3$ \\
\hline & $\begin{array}{c}\text { Maturity of } \\
\text { EAM }\end{array}$ & H3.1 & H3.2 & $\mathrm{H} 3.3$ \\
\hline
\end{tabular}

As described in chapter 2 and parts of the main literature in the enterprise architecture field one can implicitly state testable hypotheses. These are stated as benefits of enterprise architecture either for the business directly or via the impact of improved ITmanagement.

3.1.1. Successful Execution of IT-projects. Enterprise architecture management is believed to reduce the amount of IT-projects that fail within the organizations. For instance, Lankhorst [15] state that EA leads to "Reduced risk overall in new investment, and the cost of IT ownership" and to "Easier upgrade and exchange of system components". The Open Group [6] also states that EA leads to reduced risk for future investments.

The variable "Successful execution if IT-projects" was used to assess the level of IT-project risks. This variable is a composite of two items. The first addresses the average budget overrun when investing in new information technology. The second one covers the average (schedule) delay of information 
technology projects. Both are determined relative to other organizations in the same field and of the same size.

3.1.2. Duration of procurements projects. Mature enterprise architectures and thus mature enterprise architecture management has been claimed to decrease the duration of IT procurement projects. TOGAF [6] does for instance state that enterprise architecture makes the procurement process faster without sacrificing architectural coherence. TOGAF also state that risks (e.g. due to schedule overruns) are decreased with good enterprise architecture management. Zachman [16] describes the descriptive "as-is" architecture as a necessary condition for changing an enterprise safely.

The variable Duration of procurement projects was built upon the comparison of the duration for procurement to organizations of the same size and operating within the same field. One item was used to determine this variable.

3.1.3. Operational departments' satisfied with IT. The third variable associated with IT-success included in this study was the "Operational departments' satisfied with IT."

The basic notion behind enterprise architecture activities is to create a value for the enterprise. Enterprise architecture is intended to increase the return on IT-investments, reduce risks associated with IT-projects, make procurements simpler and faster, and much more. The operational departments within an enterprise are typically those that benefit from such qualities. It can also be expected that operational departments will have to bear the costs of enterprise architecture management activities, either directly or indirectly. If enterprise architecture management activities are beneficial it could therefore be expected that these make operational departments more satisfied with the IT.

This variable is defined as the satisfaction experienced by the organizations operational department when compared to the satisfaction of other organizations' operational departments.

\subsection{Enterprise architecture management activities}

Three variables were defined to assess the enterprise architecture management activities within the organization. The existence and age of the enterprise architecture management function within the organization are two of these. The maturity of enterprise architecture management is the third.
3.2.1. Existence of enterprise architecture management. In our survey we used the age of the organizational function for Enterprise Architecture Management to determine whether EAM exists or not. The participants had the possibility to state the age of their EAM on the scale \{does not exist, $<1,1$ $2,2-5,>5$ years $\}$. All positive values were treated as indicators of the existence of EAM.

3.2.2. The amount of time working with enterprise architecture management. The amount of time worked with EAM was evaluated through the same question as the one used to evaluate the existence. In contrast to a binary answer, we considered the five different time intervals to gather the actual time of the EAM duration.

3.2.3. Enterprise architecture management maturity. As described in section 2 there are several maturity models for enterprise architecture management. As the union of these produces a large number of variables, which are partly overlapping, a subset of the maturity-variables was selected.

Seven different items (questions) was used to assess the maturity level of enterprise architecture activities (cf. Table 2). These items are drawn from the following maturity frameworks: [14], [17], [18], [19], [20], and [21].

The arithmetic mean of these seven items was used. As can be seen from Table 2 the items are included in the majority of the maturity frameworks discussed earlier. For instance, all do for instance discuss the role of architects. Three out of six stress that enterprise architecture should be seen as process, hence that budgets should be provided continuously. Four out of six maturity models associate an agreed reference method to mature enterprise architecture management practices.

Table 2. Operationalization of EAM maturity.

\begin{tabular}{|l|l|}
\hline Items & From \\
\hline $\begin{array}{l}\text { The roles of the architects are } \\
\text { defined. }\end{array}$ & $\begin{array}{l}{[14][17][18]} \\
{[19][20][21]}\end{array}$ \\
\hline $\begin{array}{l}\text { Budget and resources of EAM are } \\
\text { provided continuously }\end{array}$ & {$[14][18][20]$} \\
\hline There exist defined EAM-processes. & {$[14][18][20]$} \\
\hline $\begin{array}{l}\text { (Enterprise-)Architecture models are } \\
\text { evaluated and benchmarked } \\
\text { constantly. }\end{array}$ & {$[14][17][18]$} \\
\hline $\begin{array}{l}\text { EAM-processes are evaluated and } \\
\text { benchmarked constantly. }\end{array}$ & {$[19][20]$} \\
\hline
\end{tabular}




\begin{tabular}{|l|l|}
\hline $\begin{array}{l}\text { There exist defined maintenance } \\
\text { processes for (Enterprise-) } \\
\text { Architecture models and data. }\end{array}$ & {$[14][18]$} \\
\hline $\begin{array}{l}\text { EAM is performed with use of an } \\
\text { agreed (reference-) method. }\end{array}$ & {$[19][20]$} \\
\hline
\end{tabular}

\subsection{Hypotheses}

With the above as a basis, three main hypotheses on Enterprise Architecture Management's effects on IT-success were tested proposed:

- H1: The existence of Enterprise Architecture Management function correlates with ITsuccess.

- H2: The amount of time the organization has worked with Enterprise Architecture Management correlates with IT-success.

- H3: The maturity of Enterprise Architecture Management correlates with IT-success.

These three main hypotheses are detailed into three hypotheses each to consider the three types of IT-success described above: the number of successfully executed IT-projects, the duration of procurement projects and the satisfaction of operational departments.

The first hypothesis describing the relationship between the existence of EAM and IT-success is tested through an analysis of the Hypothesis H1.1 to H1.3. The three sub-hypotheses in total capture the initial hypothesis H1, but allow a more detailed analysis. The same goes for Hypothesis $\mathrm{H} 2$ and $\mathrm{H} 3$ which are detailed in $\mathrm{H} 2.1$ to $\mathrm{H} 2.3$ and $\mathrm{H} 3.1$ to $\mathrm{H} 3.3$ respectively.

The in total nine hypotheses are:

- H1.1 - The existence of EAM correlates with the share of successfully executed ITprojects.

- H1.2 - The existence of EAM correlates with the duration of procurement projects.

- H1.3 - The existence of EAM correlates with the satisfaction of operational departments.

- H2.1 - The amount of time worked with EAM correlates with share of successfully executed IT-projects.

- H2.2 - The amount of time worked with EAM correlates with duration of procurement projects.

- H2.3 - The amount of time worked with EAM correlates with the satisfaction of operational departments.

- H3.1 - The maturity of EAM correlates with the share of successfully executed ITprojects.
- H3.2 - The maturity of EAM correlates with duration of procurement projects.

- H3.3 - The maturity of EAM correlates with the satisfaction of operational departments.

\section{Result}

The overall aim of the presented study is to test three main hypotheses (divided into nine subhypotheses) related to Enterprise Architecture Management and its effects on the organizations performance in IT projects and IT products.

\subsection{Questionnaire and data collection}

A survey questionnaire was prepared. The greater part of the questions in the survey has been used in several research projects at the University of St Gallen in Switzerland, thus also tested and iteratively improved [23]. The additions concern the questions regarding the execution of IT-projects and the ITsatisfaction in operational departments.

The survey was distributed during an Enterprise Architecture Symposium at the Royal Institute of Technology in Stockholm, Sweden the $15^{\text {th }}$ of October 2009. The symposium had 268 attendants mainly from Swedish companies. Of the 268 attendants 68 handed in surveys.

As the population used for this survey is persons attending an event there is a risk that it is biased. In particular, it can be expected to be skewed towards organizations with an interest in enterprise architecture management. Most of the respondents work in large organizations -73 percent work in organizations with more than thousand employees. Most industry areas are covered. However, as many as $69 \%$ works in an IT-department, cf. Table 3, Table 4 and Table 5.

Table 3. Survey participants by business.

\begin{tabular}{|l|r|r|}
\hline Industry & Count & Percentage \\
\hline Banking & 13 & $19 \%$ \\
\hline Commerce & 2 & $3 \%$ \\
\hline Consulting & 5 & $7 \%$ \\
\hline Energy & 3 & $4 \%$ \\
\hline Insurance & 3 & $4 \%$ \\
\hline Manufacturing & 10 & $15 \%$ \\
\hline Public Administration & 13 & $19 \%$ \\
\hline Software Vendor/Developer & 3 & $4 \%$ \\
\hline Telecommunication & 4 & $6 \%$ \\
\hline Other & 12 & $18 \%$ \\
\hline
\end{tabular}


Table 4. Survey participants by enterprise size.

\begin{tabular}{|l|r|r|}
\hline Size of company & Count & Percentage \\
\hline $20-99$ & 0 & $0 \%$ \\
\hline $100-249$ & 5 & $8 \%$ \\
\hline $250-499$ & 6 & $10 \%$ \\
\hline $500-1000$ & 6 & $10 \%$ \\
\hline$>1000$ & 19 & $30 \%$ \\
\hline$>10000$ & 26 & $42 \%$ \\
\hline
\end{tabular}

Table 5. Background of the enterprises' respondents.

\begin{tabular}{|l|r|r|}
\hline Area of activity & \multicolumn{1}{|l|}{ Count } & Percentage \\
\hline IT-department & 46 & $69 \%$ \\
\hline Management & 6 & $9 \%$ \\
\hline Operational dep. & 8 & $12 \%$ \\
\hline Other & 7 & $10 \%$ \\
\hline
\end{tabular}

The demographical differences between the survey respondents were not considered in the analysis. However, this could be an interesting follow up analysis, since there might be significant trends to be found in these differences.

The survey consisted of three parts. Part one contained questions regarding the background of the respondents such as industry and company. The second part contained five questions regarding ITinvestments and IT-procurement. Part three of the survey had five sections. These five sections addressed the Introduction, Understanding, Organization, Functions and Planning processes of Enterprise Architecture Management. For each statement the respondents were asked to mark the current and target situation on a five-point Likert scale (where 1 represent strongly disagree, 2 disagree, 3 partly agree, 4 agree and 5 equals strongly agree).

\subsection{Validity and reliability}

The variables chosen for testing the hypotheses are described in section 3. This data set was screened according to the checklist provided by [26], e.g. proofreading worksheet against original data sources, checking for outliers, missing values and normality. The test for normality was implemented by printing histograms quantile-quantile plots for all studied variables. These tests showed normality.

As the questionnaire used for this study is based on questionnaire that has been used and tested multiple times in earlier studies the reliability of the origin is to a certain extent transferable. However, three elements were added to assess the output produced in terms of information system deliverables. Two of these were combined into the variable Successful Execution of IT-projects and seven of the original elements were combined into the variable survey Enterprise Architecture Management Maturity. The reliability of these two items was measured with the Cronbach's Alpha reliability coefficient, originally proposed in 1951 [27] and revised and discussed in [28]. Table 6 shows the result of this test.

Table 6 Reliability assessment using Cronbach's Alpha.

\begin{tabular}{|c|c|c|}
\hline Variable & Items & $\alpha$ \\
\hline \multirow{7}{*}{$\begin{array}{l}\text { EAM } \\
\text { Maturity }\end{array}$} & $\begin{array}{l}\text { The role of the architects is } \\
\text { defined. }\end{array}$ & \multirow{7}{*}{0.881} \\
\hline & $\begin{array}{l}\text { Budget and resources of EAM } \\
\text { are provided continuously }\end{array}$ & \\
\hline & $\begin{array}{l}\text { There exist defined EAM- } \\
\text { processes. }\end{array}$ & \\
\hline & $\begin{array}{l}\text { (Enterprise-)Architecture } \\
\text { models are evaluated and } \\
\text { benchmarked constantly. }\end{array}$ & \\
\hline & $\begin{array}{l}\text { EAM-processes are evaluated } \\
\text { and benchmarked constantly. }\end{array}$ & \\
\hline & $\begin{array}{l}\text { There exist defined } \\
\text { maintenance processes for } \\
\text { (Enterprise) Architecture } \\
\text { models and data. }\end{array}$ & \\
\hline & $\begin{array}{l}\text { EAM is performed with use } \\
\text { of an agreed (reference) } \\
\text { method. }\end{array}$ & \\
\hline \multirow{2}{*}{$\begin{array}{l}\text { Successful } \\
\text { Execution } \\
\text { of IT }\end{array}$} & $\begin{array}{l}\text { Compared to other } \\
\text { organizations within the same } \\
\text { sector and of the same size, } \\
\text { my organization has a low } \\
\text { average budget overrun when } \\
\text { investing in new information } \\
\text { technology. }\end{array}$ & \multirow{2}{*}{0.717} \\
\hline & $\begin{array}{l}\text { Compared to other } \\
\text { organizations within the same } \\
\text { sector and of the same size, } \\
\text { my organization has a low } \\
\text { average (schedule) delay of } \\
\text { information technology } \\
\text { projects. }\end{array}$ & \\
\hline
\end{tabular}

The threshold of the Alpha coefficient is dependent on the number of items being assessed. 
Interpreting the results of Cortina [29], seven items with Alpha 0.881 and two items at 0.717 gives an acceptable reliability level.

As described in chapter 2 , there is no consensus on how to measure the maturity of enterprise architecture management, i.e. what items Enterprise Architecture Management Maturity should comprise of. As no standard has been commonly accepted it difficult to test content. As outlined in section 3 the items included in this survey are all well represented in frameworks developed to measure this variable. While they do not cover all the elements that different frameworks find relevant they capture a number of essential variables.

The lack for commonly accepted maturitymeasurement standards makes it difficult to test convergent validity for the used EAM maturity variable.

To test disciminant validity one would like to ensure that the used measure for enterprise architecture management maturity is different from measures of variables that are similar to enterprise architecture management maturity but represent some other construct. IT governance is a discipline closely related to enterprise architecture management and a test for disciminant validity could ensure that the operationalization used in this study is different from IT governance maturity. However, as no commonly accepted standards for IT governance maturity exists either, such tests are difficult to construct. However, the items of EAM maturity focus on architects and enterprise architecture management processes. As these aspects are not the locus of IT governance frameworks it appears as unlikely that disciminant validity is threatened. Also, the context under which the respondents filled in the survey (an enterprise architecture symposium) make reasonable to believe that the respondents provided answers that reflect their work within enterprise architecture management.

The operationalization of successful executed projects used in this study is a composite of projects being on time and within budget. According to the most common definition of successful projects the quality delivered should also be included in this operationalization. There are also many alternative definitions of project success [30]. In relation to these the operationalization used in this study only cover a part of the construct "Successful IT project".

\subsection{Test result}

The hypotheses were tested with standard bivariate two-tailed Pearson correlation. The results are presented in Table 7.
As can be seen in Table 7 the number of responses varies between 42 and 57 for the different hypotheses. There majority of these correlations are both weak and insignificant. The hypotheses with strongest correlation are those related to hypothesis 3 - the influence of mature enterprise architecture management on IT success. The two strongest correlations, H3.2 and $\mathrm{H} 3.3$, are also significant to the 0.05 -level. Hypothesis H3.1 is almost significant to the 0.10 -level.

\section{Discussion and research outlook}

This section is divided into three parts: discussion of results, industrial and academic impact and future work.

Table 7. Pearson correlation for each hypothesis.

\begin{tabular}{|l|r|r|l|}
\hline Hypothesis & Pearson Correlation & Sig. (2-tailed) & N \\
\hline H1.1 & 0.092 & 0.506 & 55 \\
\hline H1.2 & 0.074 & 0.633 & 44 \\
\hline H1.3 & -0.088 & 0.513 & 57 \\
\hline H2.1 & -0.090 & 0.563 & 44 \\
\hline H2.2 & -0.121 & 0.441 & 43 \\
\hline H2.3 &.$a$ & 0.000 & 42 \\
\hline H3.1 & 0.238 & 0.104 & 48 \\
\hline H3.2 & $0.304 *$ & 0.035 & 48 \\
\hline H3.3 & $0.292 *$ & 0.044 & 48 \\
\hline
\end{tabular}

.a Cannot be computed because at least one of the variables is constant.

* Correlation is significant at the 0.05 level (2-tailed).

$\mathrm{N}$ Represents the number of respondents answering questions used to test this hypothesis.

\subsection{Results discussion}

Our study indicates that the mere existence of an enterprise architecture function at a company is not enough if the goal is to have IT-success. The results found also indicate that having an enterprise architecture function for a long time will not impact the success of IT. However, since the correlations are insignificant these two results do not mean that the two related hypotheses tested can be rejected.

Dividing the three main hypotheses our study shows that the enterprise architecture management maturity correlates with all three IT-success measures, namely successful execution of ITprojects, duration of procurement projects and 
operational departments' satisfied with IT, whereas the last two of these are signification at the 0.05 level.

A common question to ask when performing statistical studies like this is if the correlations found also indicate causality. It appears unlikely that the correlation is due to an inverse causality, e.g. that business satisfaction caused the enterprise architecture management maturity. No theory studied did either suggest this. It is of course possible that some other (third, unmeasured) factor causes the found correlation. However, it is not easy to come up with such a relationship that at the same time corroborates $\mathrm{H} 3$ and rejects $\mathrm{H} 1$ and $\mathrm{H} 2$. For example, that the organization is "rich" could perhaps explain a satisfied business (because they are not under stress in general and that there is enough room for having time to develop a mature enterprise architecture management), but with these arguments there is no explanation of the lack of correlation with the existence of enterprise architecture management.

However, given that the correlation was not very strong, it is apparent that IT-project success and business satisfaction also depends on other factors than enterprise architecture management maturity.

\subsection{Industrial and academic impact}

For the practitioner this study indicates that when working with enterprise architecture it is important to be active and aim at a mature enterprise architecture management function. Time itself will not do the trick. The definition used in this study of EAM can guide a practitioner in EAM maturity work.

In academia enterprise architecture is getting more and more research focus. This study shows that researchers working with enterprise architecture management are doing important research for industry, since enterprise architecture management can help companies become better at IT. This study can also help researchers to focus their studies. For instance, since enterprise architecture management maturity shows significant correlation with ITsuccess researchers can help practitioners by studying how the maturity items can be implemented successfully.

\subsection{Future work}

The definition chosen for enterprise architecture management maturity in this study consists of seven items all widely considered in enterprise architecture research literature. However, others might use a different definition than the one employed here. Thus, a future study could test the same hypotheses with slightly different maturity definitions to test if the correlation still exists.

Further, the IT-project success definition might be considered by some to be incomplete. For instance, some might argue that project quality is not addressed sufficient enough. It is partly covered by the subjective measure of operational department happiness. Still, this can also be addressed in a future study. Moreover the metric used here is relative. It might still be the case the project success is quite poor in absolute terms.

In this study company representatives were surveyed during a symposium focusing on enterprise architecture. It is our firm belief that the organizations at the symposium provide a good enough sample giving survey answers which indicates the impact of enterprise architecture management on IT-success. However, in order to get a more representative population for the analysis and a larger sample of enterprises the study could be done in another way, for example by sending the survey to a random set of organizations.

In addition to corroborate the findings presented here, interesting further work is to dig deeper into the concept of maturity and investigate if there exists any specific aspect(s) of "being mature" that impacts the success of running IT satisfaction of the business. How important is for instance the use of models for enterprise architecture management? Is it more or less important than for instance the enterprise architecture management processes? In other words, are there any success factors for enterprise architecture management? Moreover, with a better understanding of the importance of "smaller units" of maturity it might also be possible to build up an empirically based enterprise architecture management maturity model. If it turns out that models for instance are of no help unless there is a process in place, this should be reflected in a maturity index in order to make it really useful for the practitioners.

\section{Conclusions}

This paper provides an empirical argument for the hypothesis that enterprise architecture management needs to be mature in order to have effect. On the other hand, the mere existence of enterprise architecture work has not been found to have an impact. Nor does the amount of time the enterprise architecture function has existed appear to impact the success of IT within enterprises.

These conclusions are based on data collected during an event in Stockholm 2009. Future work could the findings in this study with a more 
representative and encompassing population of enterprises. Further work could also be made on the development and of validation measurement instruments for measuring enterprise architecture management activities and their impact.

\section{References}

[1] J.W. Ross, P. Weill, and D.C. Robertson, Enterprise architecture as strategy: Creating a foundation for business execution, Massachusetts, USA: Harvard Business School Press, 2006.

[2] S. Kurpjuweit and R. Winter, "Viewpointbased meta model engineering," EMISA 2007, 2007.

[3] R. Winter and R. Fischer, "Essential Layers, Artifacts, and Dependencies of Enterprise Architecture," Journal of Enterprise Architecture, vol. 3, 2007, p. 7-18.

[4] H. Koning, R. Bos, and S. Brinkkemper, "A Lightweight Method for the Modeling of Enterprise Architectures: Introduction and Empirical Validation," Utrecht: Department of Information and, 2006.

[5] F. Theuerkorn, Lightweight enterprise architectures, CRC Press, 2004.

[6] TOGAF, The Open Group Architecture Framework (TOGAF) - version 9, The Open Group, 2009.

[7] D. Hinchcliffe, "Pragmatic new models for enterprise architecture take shape," 2009.

[8] Gartner, "Gartner Hype Cycle for Enterprise Architecture 2010," 2010.

[9] S.H. Spewak, Enterprise Architecture Planning, Princeton, NJ, USA,: John Wiley and Sons, inc., 1992.

[10] M. Lankhorst, Enterprise architecture at work: Modelling, communication and analysis, Heidelberg, Berlin, Germany: Springer-Verlag, 2009.

[11] W. Boh and D. Yellin, "Using Enterprise Architecture Standards in Managing Information Technology," Journal of Management Information Systems, vol. 23, 2007, pp. 163-207.

[12] R. Lagerström, "Enterprise Systems Modifiability Analysis - An Enterprise Architecture Modeling Approach for Decision Making," Architecture, 2010.

[13] MoD, "MODAF Handbook, technical specification for MODAF," 2005.

[14] DoC, "Enterprise Architecture Program Support," 2007.
[15] TOGAF, ArchiMate Technical Specification, van Haren Publishing, 2009.

[16] J.A. Zachman, "Enterprise architecture: The issue of the century," Database Programming and Design, vol. 10, 1997, pp. 44-55.

[17] US Goverment Accountability Office, "A Framework for Assessing and Improving Enterprise Architecture Management," 2003.

[18] M.E. van Steenbergen, "Architecture Maturity Matrix - DYA," 2005.

[19] M. van Steenbergen, M. van Den Berg, and S. Brinkkemper, "An instrument for the development of the enterprise architecture practice," ICEIS, Funchal, Madeira, Portugal: 2007, pp. 12-16.

[20] J. Schekkerman, "Extended Enterprise Architecture Maturity Model Support Guide v2. 0," 2006.

[21] NASCIO, "NASCIO Enterprise Architecture Maturity Model, v 1.3," 2003.

[22] R. Slot, G. Dedene, and R. Maes, "Business Value of Solution Architecture," E. Proper, F. Harmsen, and J.L. Dietz, Berlin/Heidelberg, Germany: Springer Verlag, 2009, pp. 84-108.

[23] C. Riege and S. Aier, "A Contingency Approach to Enterprise Architecture Method Engineering," Pre-Proceedings of the 3rd Workshop on Trends in Enterprise Architecture Research (TEAR 2008), Dec 1, 2008 , in conjunction with the 6th International Conference on Service Oriented Computing (ICSOC08), Sydney, Australia: Springer, 2009, pp. 388-399.

[24] S. Aier, C. Riege, and R. Winter, "Classification of Enterprise Architecture Scenarios-An Exploratory Analysis," Enterprise Modelling and Information Systems Architectures, vol. 3, 2008, p. 1423.

[25] S. Aier, C. Riege, and R. Winter, "Unternehmensarchitektur Literaturüberblick und Stand der Praxis," Wirtschaftsinformatik, vol. 50, 2008, pp. 292-304.

[26] R. Warner, Applied Statistics - From Bivariate Through Multivariate Techniques, London: SAGE Publications Inc., 2008.

[27] L.J. Cronbach, "Coefficient alpha and the internal structure of tests," Psychometrika, vol. 16, 1951, pp. 297-334.

[28] L.J. Cronbach and R.J. Shavelson, "My Current Thoughts on Coefficient Alpha and Successor Procedures," Educational and 
Psychological Measurement, vol. 64, 2004, pp. 391-418.

[29] J.M. Cortina, "What is coefficient alpha? An examination of theory and applications.,"

Journal of Applied Psychology, vol. 78, 1993, pp. 98-104.

[30] R. Atkinson, "Project management: cost, time and quality, two best guesses and a phenomenon, its time to accept other success criteria," International Journal of Project

Management, vol. 17, 1999, pp. 337-342. 